\title{
Targeting heart failure with preserved ejection fraction: current status and future prospects
}

\author{
This article was published in the following Dove Press journal: \\ Vascular Health and Risk Management \\ 15 April 2016 \\ Number of times this article has been viewed
}

\author{
Manreet Kanwar \\ Claire Walter \\ Megan Clarke \\ Maria Patarroyo-Aponte \\ Department of Cardiology, Allegheny \\ General Hospital, Pittsburgh, PA, USA
}

Correspondence: Manreet Kanwar Department of Cardiology, Allegheny General Hospital, 320 E North Avenue, Pittsburgh, PA I5212, USA

Tel + I 4I23594760

Fax + I 4I23596544

Email mkanwar@wpahs.org
Abstract: Heart failure with preserved ejection fraction (HFpEF) portrays a significant burden in terms of prevalence, morbidity, mortality, and health care costs. There is a lack of consensus on the basic pathophysiology, definition, and therapeutic targets for therapy for this syndrome. To date, there are no approved therapies available for reducing mortality or hospitalization for these patients. Several clinical trials have recently started to try and bridge this major gap. There is an urgent need to focus on drug and device development for HFpEF as well as to understand HFpEF pathophysiology.

Keywords: HFpEF therapies, diastolic dysfunction

\section{Introduction}

Congestive heart failure (HF) is a growing epidemiologic problem and a major source of morbidity, mortality, and health care expenditure. ${ }^{1}$ Approximately 5.1 million people in the United States carry a diagnosis of HF, and the prevalence continues to rise. HF with reduced ejection fraction (HFrEF) and $\mathrm{HF}$ with preserved $\mathrm{EF}(\mathrm{HFpEF})$ each make up about one-half of the overall HF burden. Randomized clinical trials in patients with HF have mainly enrolled patients with HFrEF, and it is only in these patients that efficacious therapies have been demonstrated to date. Unlike with HFrEF, there have been no medical or surgical therapies shown to improve survival in patients with HFpEF. With its rising role in health care expenditure and increasing complexity of patients, there is a critical need for new drug and device therapies for HFpEF.

\section{Epidemiology}

The growth of the HF population is in part attributable to a changing demography, with HF being most prevalent in the elderly. In addition, the past 2 decades have also seen an increasing burden of common HF risk factors such as hypertension, diabetes, coronary artery disease, obesity, sleep apnea, and valvular heart disease. In addition, hospitalizations for HFpEF have also increased over time. These patients have a longer length of stay and are more likely to require skilled nursing care. ${ }^{1}$ Although mortality in HFpEF patients appears to be somewhat lower than the mortality in those with HFrEF in outpatient cohorts, observational studies now show a higher mortality in these patients than that seen in clinical trials. ${ }^{2,3}$

\section{Pathophysiology}

$\mathrm{HFpEF}$ is mostly related to the abnormal diastolic function of the left ventricle (LV) dysfunction and increase in arterial stiffness, which will lead to an abnormal 
ventricular-arterial (V-A) coupling. ${ }^{4-6}$ In addition, these patients will have an abnormal LV systolic performance and chronotropic incompetence, which contribute to their abnormal exercise response (Figure 1).

\section{Diastolic dysfunction}

Diastolic dysfunction is the result of several comorbidities, including diabetes mellitus, hypertension, obesity, and chronic kidney disease, which induce a systemic inflammatory state with high circulating levels of interleukin- 6 and tumor necrosis factor- $\alpha$. This inflammatory state leads to coronary microvascular endothelial dysfunction with reduced vasodilator response to acetylcholine as a result of low nitric oxide (NO) bioavailability and increase in reactive oxygen species production. In addition, low NO bioavailability leads to decreased activity of protein kinase $\mathrm{G}$ and cyclic guanosine monophosphate (cGMP), which ultimately cause cardiomyocyte hypertrophy and fibrosis with increased stiffness and subsequent diastolic dysfunction. ${ }^{7,8}$ This cardiomyocyte stiffness has been related to an increase in the proportion of N2BA isoform of titin, a large protein that links the thick filaments of sarcomeres to the adjacent Z-disks, compared to its isoform $\mathrm{N} 2 \mathrm{~B}$. This protein switching has been proposed as a myocardial mechanism to adjust for passive stiffness. However, in patients with HFpEF, the excess of protein kinase $\mathrm{C}$ and decrease in protein kinase $\mathrm{G}$ lead to a decrease in titin phosphorylation and thereby to an increase in the passive stiffness of titin. ${ }^{9,10}$
Myocardial stiffness is not just related to cardiomyocyte stiffness but also to extracellular matrix changes, which in turn are determined by the amount of collagen and the extent of collagen cross-linking. ${ }^{7,11}$ In HFpEF, there is an increase in collagen type I, which results from an increase in its synthesis, depending on the activation of collagen-typespecific genes, and a decrease in its degradation secondary to a downregulation of matrix metalloproteinases. ${ }^{12}$ Finally, diastolic dysfunction will also be the result of an abnormal active process of relaxation related to an abnormal calcium handling mechanism, which causes an increase in resting calcium concentrations, mostly related to decreased expression of sarcoendoplasmic reticulum calcium-ATPase and phospholamban as well as increased function of the sodium/potassium pump exchanger, which contributes to the increased intracellular calcium loading. ${ }^{6}$

\section{Arterial stiffness}

Patients with HFpEF have impaired flow-mediated vasodilation and reduced aortic distensibility compared to healthy controls. ${ }^{13}$ This vascular dysfunction is related to endothelial dysfunction secondary to the decrease in NO bioavailability and can affect both proximal and distal arteries. ${ }^{6,13}$ This increase in stiffness and decrease in arterial compliance lead to an abnormal vasodilator response to exercise, which causes augmented pulse pressure waves and hemodynamic abnormalities that impair more the diastolic function of the LV and

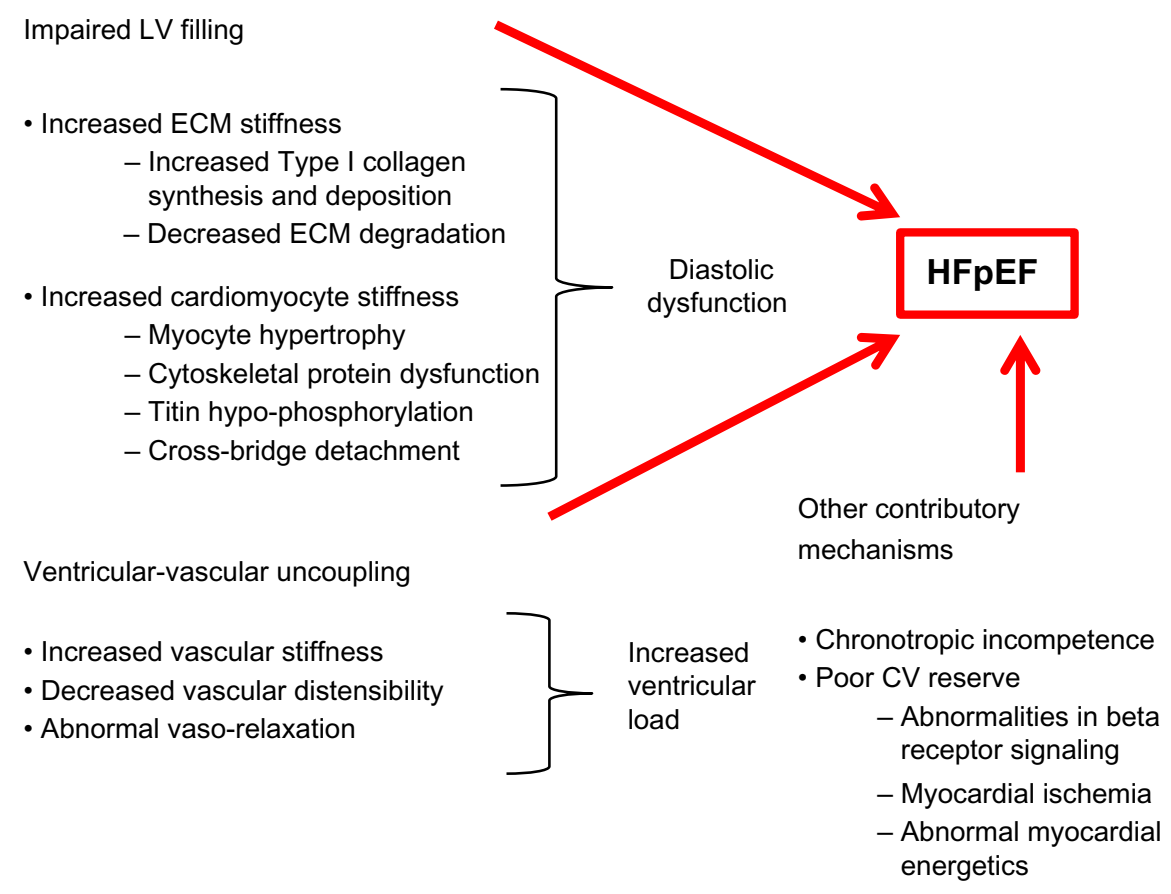

Figure I Multiple factors that contribute to the pathophysiology of HFpEF.

Abbreviations: LV, left ventricular; ECM, extracellular matrix; HFpEF, Heart failure with preserved ejection fraction; CV, cardiovascular. 
decrease peripheral-mediated vasodilation and, consequently, a decrease in blood flow to the skeletal muscle..$^{14,15}$

\section{V-A coupling}

As mentioned earlier, the principal physiologic mechanism for $\mathrm{HFpEF}$ is an abnormal $\mathrm{V}-\mathrm{A}$ coupling that results from $\mathrm{LV}$ and arterial stiffness (Figure 2). It refers to the interaction between the heart and the vascular system in order to provide the maximal working efficiency. In an optimal situation, $\mathrm{V}-\mathrm{A}$ coupling allows the transfer of blood from the heart to the vascular system without excessive changes in blood pressure. It also provides an optimal cardiovascular (CV) reserve without affecting blood pressure with the minimum possible energy consumption. ${ }^{6,15}$ Normally, both the ventricular and arterial elastance are closely matched to get the optimal efficiency with a normal $E_{\mathrm{a}} / E_{\mathrm{es}}$ ratio of 0.5-1.0. In patients with $\mathrm{HFpEF}$, the ventricular elastance $\left(E_{\mathrm{es}}\right)$ and arterial elastance $\left(E_{\mathrm{a}}\right)$ are elevated compared with normal individuals but the ratio is $\sim 0.5$, indicating that the system is already working at its maximal efficiency, compared with patients with HFrEF in whom the $E_{\mathrm{a}} / E_{\mathrm{es}}$ ratio is fivefold higher, indicating more afterload mismatch. ${ }^{16}$ This translates into systolic pressures that are more sensitive to changes in the LV end diastolic volume, and this small change in volume causes excessive changes in blood pressure. Also, small changes in ventricular elastance will cause large changes in blood pressure without significant change in stroke volume (SV), leading to an increase in myocardial oxygen consumption. ${ }^{15}$ These characteristics of the ventricular-vascular coupling lead to different results when vasodilators are administered to these patients. As demonstrated by Schwartzenberg et al, when nitroprusside was given to patients with $\mathrm{HFpEF}$ and HFrEF, although both groups showed similar reduction in blood pressure, patients with HFpEF had a greater drop in systolic blood pressure ( $\sim 2.5$ fold $)$ and mean arterial pressure
( $\sim 1.5$ fold) compared to those with HFrEF. However, HFrEF patients had a threefold increase in SV and cardiac output (CO) while patients with HFpEF had a very small increase in SV, and almost $35 \%$ of them had a decrease in SV. Therefore, except for patients with pulmonary edema and severe hypertension, the use of vasodilators could lead to increased risk of hypotension or drop in SV.

\section{Chronotropic incompetence}

Patients with HFpEF elicit a chronotropic incompetence, which is related to decreased $\beta$-adrenergic stimulation during exercise due to increased baseline plasma catecholamines and autonomic dysfunction secondary to baroreflex sensitivity. ${ }^{17}$ In fact, patients with HFpEF had a $40 \%$ less of an increase in heart rate and $\mathrm{CO}$ during exercise compared with matched controls, and their heart rate recovery after exercise was delayed. Thus, in these patients, exercising capacity correlated with the change in $\mathrm{CO}$, heart rate, and vascular resistance but not end-diastolic volume. ${ }^{17}$

\section{Abnormal LV systolic function}

In hypertensive patients without HF, the myocardial contractility is increased, while in HFpEF patients the contractility is reduced. Increase in passive stiffness leads to decrease in contractility and abnormal systolic reserve, which has been associated with the inability to increase EF in response to exercise or beta-adrenergic stimulation and associated with an increase in mortality in these patients. ${ }^{18}$ These findings of abnormal systolic function were described by Yu et al, ${ }^{19}$ who found that patients with diastolic dysfunction have abnormal tissue Doppler indices suggestive of systolic dysfunction. More recently, it has been demonstrated that patients with HFpEF have significantly lower longitudinal strain and circumferential strain on tissue Doppler compared with normal controls and patients with hypertensive heart disease. ${ }^{20}$
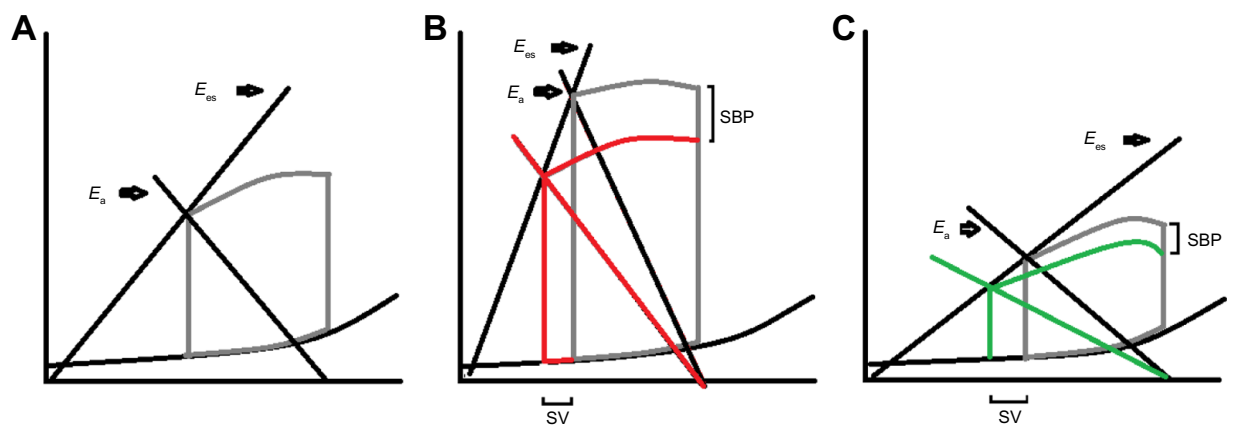

Figure 2 Effect of changes in arterial elastance $\left(E_{\mathrm{a}}\right)$ in SBP and SV.

Notes: (A) Normal pressure-volume curve showing the relation between $E_{\mathrm{a}}$ and $E_{\mathrm{es}}$. (B) Pressure-volume curve in a patient with $\mathrm{HFp} E \mathrm{EF}$ showing a significant drop in $\mathrm{SBP}$ with mild increase in SV after decrease in $E_{\mathrm{a}}$ (red line). (C) Pressure-volume curve in a patient with HFrEF with increase in SV and minimal change in SBP after decrease in $E_{\mathrm{a}}$ with vasodilator therapy.

Abbreviations: SBP, systolic blood pressure; SV, stroke volume; HFpEF, heart failure with preserved ejection fraction; HFrEF, heart failure with reduced ejection fraction. 
Right ventricle and pulmonary hypertension Community-based studies have shown that $83 \%$ of patients with HFpEF have associated pulmonary hypertension. In these patients, the increase in pulmonary pressures is associated with passive increase in pulmonary vein pressure but also with increase in pulmonary artery resistance, which leads to "out of proportion" pulmonary hypertension. Also, it has been demonstrated that the increase in pulmonary wedge pressure seen in these patients has an impact on the compliance-resistance relation in the pulmonary vasculature. ${ }^{21}$ This leads to a bigger decline in compliance, causing significant changes in pulmonary arterial pulsatile load and, therefore, in right ventricular systolic load. ${ }^{22}$ The final result of these hemodynamic changes is right ventricular dysfunction, which leads to worse prognosis. In fact, one-third of patients with HFpEF had right ventricular dysfunction, which was related to higher right atrial volumes, greater ventricular dilatation, increase in diastolic stiffness, and higher mortality compared with patients without right ventricular dysfunction. It is also important to know that some of these patients with normal pulmonary wedge pressure at rest can have an increase in wedge pressure during exercise or after fluid bolus, which can lead to underdiagnosis of pulmonary hypertension related to left heart disease in such patients. ${ }^{23}$

\section{Diagnosis}

The diagnosis of HFpEF is made in patients with signs or symptoms of HF, left ventricle ejection fraction (LVEF) $>50 \%$, and evidence of diastolic dysfunction. ${ }^{24}$ Echocardiography provides information regarding the LV function and diastolic dysfunction, but it also can give information regarding V-A coupling. ${ }^{25,26}$ An LVEF $>50 \%$ obtained following the American Society of Echocardiography guidelines is considered normal or mildly abnormal and should be used as the cutoff value to define HFpEF. ${ }^{25,27}$ Cardiac myocytes produce pro-brain natriuretic peptide (BNP) in response to an increase of atrial or ventricular diastolic stretch, which is subsequently cleaved in the blood into N-terminal pro-brain natriuretic peptide (NT-proBNP) and BNP. In patients with HFpEF, NT-proBNP values correlate with diastolic relaxation indices including LV end-diastolic pressure and LV relation. In fact, progressively higher values were observed in patients with a mitral valve flow velocity pattern of impaired LV relaxation, pseudo-normalization, or restriction. ${ }^{28}$

In terms of diastolic dysfunction, assessment of several echocardiographic measurements can help with the diagnosis. An $E / E^{\prime}>15$ provides evidence of diastolic dysfunction ( $83 \%$ sensitivity and $92 \%$ specificity). ${ }^{29}$ On the other hand, a septal $e^{\prime} \geq 8$, lateral $e^{\prime} \geq 10$, and a left atrial (LA) volume $<34 \mathrm{~mL} / \mathrm{m}^{2}$ are compatible with a normal diastolic function. ${ }^{27}$ The European guidelines recommend making the diagnosis of HFpEF when $E / E^{\prime}>15$ and excluding it when $E / E^{\prime}<8$. When $E / E^{\prime}$ is between 8 and 15 , the addition of biomarkers such as elevated NT-pro BNP $(>220 \mathrm{pg} / \mathrm{mL})$ or BNP $(>200 \mathrm{pg} / \mathrm{mL}$ ) will help diagnose HFpEF. If the biomarkers are lower, then additional echocardiographic information, such as $E / A<0.5$, deceleration time $>280 \mathrm{~ms}$, or left atrial volume index $>40 \mathrm{~mL} / \mathrm{m}^{2}$ or LV myocardial infarction (MI) $>122 \mathrm{~g} / \mathrm{m}^{2}$ in women and $>149 \mathrm{~g} / \mathrm{m}^{2}$ in men, or the presence of atrial fibrillation can confirm the diagnosis. ${ }^{25}$

Another imaging modality that can help with the diagnosis of HF, especially on those patients with difficult echocardiographic windows, is cardiac MRI. Cardiac MRI is the gold standard for evaluation of LV volume, LA volume, and LV mass measurements and provides several measurements similar to echocardiogram, including transmitral and pulmonary vein flow, LA volume, strain, strain rate, and torsion. ${ }^{30}$

\section{Treatment}

\section{Current guidelines}

Unlike the management of HFrEF, there is a paucity of large evidence-based trials demonstrating morbidity and mortality benefit for the treatment of HFpEF. Several ongoing trials with existing and novel agents are trying to fulfill this unmet need (Table 1). Current guidelines for the management of HFpEF recommend management of volume status with appropriate diuretic dosing; control of blood pressure; treatment of contributing risk factors such as sleep apnea, coronary artery disease, and valvular disease; and dietary education. ${ }^{31}$

While all patients with HFpEF should be treated for underlying risk factors and comorbidities, hypertension is likely the most important to control. The American College of Cardiology Foundation/American Heart Association (ACCF/ AHA) guidelines support the use of beta-blockers, angiotensin converting enzyme (ACE) inhibitors, and angiotensin receptor blocker (ARBs) for hypertension (IIa recommendation), and recommend ARBs be considered to decrease hospitalizations (IIb recommendation) ${ }^{31}$ The Heart Failure Society of America guidelines support ACE inhibitors or ARBs be considered in all patients with symptomatic atherosclerotic disease or diabetes and one additional risk factor. ${ }^{32}$ Beta-blockers are recommended for HFpEF patients with a history of myocardial infarction (MI), hypertension, or atrial fibrillation. The European Society of Cardiology guidelines have similar recommendations. These guidelines support the use of diuretics for symptom control. ${ }^{33}$ They also recognize the importance of 
Table I Ongoing clinical trials in patients with HFpEF

\begin{tabular}{|c|c|c|c|c|}
\hline Treatment & $\begin{array}{l}\text { Clinical trial } \\
\text { identifier }\end{array}$ & $\begin{array}{l}\text { Estimated } \\
\text { enrollment, } \\
\text { phase }\end{array}$ & Objective & Primary outcome \\
\hline LCZ696 (neprilysin inhibitor) & NCT0I9207II & $\begin{array}{l}\mathrm{n}=4,300 \\
\text { Phase III }\end{array}$ & $\begin{array}{l}\text { To evaluate the effect of LCZ696 } \\
\text { compared to valsartan in the reduction } \\
\text { of CV death and HF hospitalizations }\end{array}$ & $\begin{array}{l}\text { Cumulative number of primary composite } \\
\text { events of } \mathrm{CV} \text { death and total (first and } \\
\text { recurrent) HF hospitalizations }\end{array}$ \\
\hline $\begin{array}{l}\text { Vericiguat (soluble guanylate } \\
\text { cyclase stimulator) }\end{array}$ & NCT0I95I638 & $\begin{array}{l}\mathrm{n}=477 \\
\text { Phase II }\end{array}$ & $\begin{array}{l}\text { To find the optimal dose of once daily } \\
\text { oral soluble guanylate cyclase stimulator }\end{array}$ & $\begin{array}{l}\text { Change of log-transformed NT-proBNP } \\
\text { and left atrial volume }\end{array}$ \\
\hline $\begin{array}{l}\text { Anakinra (IL-I receptor } \\
\text { antagonist) }\end{array}$ & NCT02I 73548 & $\begin{array}{l}\mathrm{n}=60 \\
\text { Phase II }\end{array}$ & $\begin{array}{l}\text { To determine effects on CV function of } \\
\text { anti-inflammatory IL-I blockade }\end{array}$ & $\begin{array}{l}\text { Absolute changes in aerobic exercise } \\
\text { capacity (peak } \mathrm{VO}_{2} \text { ) after } 12 \text { weeks and } \\
\text { absolute changes in } \mathrm{VE} / \mathrm{VCO}_{2} \text { after } 12 \\
\text { weeks treatment }\end{array}$ \\
\hline $\begin{array}{l}\text { Udenafil (phosphodiesterase } \\
5 \text { inhibitor) }\end{array}$ & NCT0I599II7 & $\begin{array}{l}\mathrm{n}=52 \\
\text { Phase III }\end{array}$ & $\begin{array}{l}\text { To determine if udenafil will improve } \\
\text { symptoms, exercise capacity, and } \\
\text { hemodynamic status in HFpEF }\end{array}$ & $\begin{array}{l}\text { Change of maximal } \mathrm{VO}_{2} \text { in } \\
\text { cardiopulmonary exercise test }\end{array}$ \\
\hline Furosemide \pm dopamine & NCT0I90I809 & $\begin{array}{l}\mathrm{n}=120 \\
\text { Phase IV }\end{array}$ & $\begin{array}{l}\text { To test the hypothesis that changing the } \\
\text { method of diuresis (continuous vs bolus) } \\
\text { with or without low-dose dopamine will } \\
\text { reduce renal injury }\end{array}$ & $\begin{array}{l}\text { Change in glomerular filtration rate at } \\
72 \text { hours }\end{array}$ \\
\hline $\begin{array}{l}\text { Isosorbide dinitrate } \pm \\
\text { hydralazine }\end{array}$ & NCT0I5I6346 & $\begin{array}{l}n=54 \\
\text { Phase II }\end{array}$ & $\begin{array}{l}\text { To test effect of prolonged isosorbide } \\
\text { dinitrate } \pm \text { hydralazine therapy ( } 24 \text { weeks) } \\
\text { on arterial wave reflections }\end{array}$ & $\begin{array}{l}\text { Change in late systolic load from wave } \\
\text { reflections between baseline and after } \\
24 \text { weeks of randomized therapy }\end{array}$ \\
\hline Inorganic nitrate & NCT02256345 & $\begin{array}{l}\mathrm{n}=12 \\
\text { Phase II }\end{array}$ & $\begin{array}{l}\text { To determine the safety, tolerability, and } \\
\text { dose-response to inorganic nitrate on } \\
\text { exercise capacity in HFpEF }\end{array}$ & $\begin{array}{l}\text { Change in peak } \mathrm{VO}_{2} \text { from baseline to } \\
\text { the end of I week of administration for } \\
\text { each dose }\end{array}$ \\
\hline Inhaled sodium nitrite & NCT02262078 & $\begin{array}{l}\mathrm{n}=30 \\
\text { Phase II }\end{array}$ & $\begin{array}{l}\text { To assess the effects of nebulized inhaled } \\
\text { nitrite administration on resting and } \\
\text { exercise hemodynamics }\end{array}$ & $\begin{array}{l}\text { Exercise pulmonary capillary wedge } \\
\text { pressure }\end{array}$ \\
\hline Ranolazine & NCT0I505I79 & $\mathrm{n}=40$ & $\begin{array}{l}\text { To determine whether treatment with } \\
\text { ranolazine will improve exercise capacity }\end{array}$ & $\begin{array}{l}\text { Change in exercise capacity from baseline } \\
\text { at } 6 \text { weeks }\end{array}$ \\
\hline Nifedipine & NCTOII5748I & $n=226$ & $\begin{array}{l}\text { To determine if nifedipine can improve } \\
\text { HF clinical response }\end{array}$ & HF clinical composite response endpoint \\
\hline Nebivolol & NCT02053246 & $\begin{array}{l}\mathrm{n}=40 \\
\text { Phase IV }\end{array}$ & $\begin{array}{l}\text { To determine if nebivolol will improve } \\
\text { disease severity in patients with } \\
\text { pulmonary hypertension associated } \\
\text { with HFpEF }\end{array}$ & Changes in pulmonary vascular pressure \\
\hline Carvedilol vs nebivolol & NCT02619526 & $n=62$ & $\begin{array}{l}\text { To compare the relative effectiveness of } \\
\text { carvedilol and nebivolol in treating } \mathrm{HF} \text { in } \\
\text { aged patients with preserved } \mathrm{EF}\end{array}$ & $\begin{array}{l}\text { Ratio of transmitral E velocity to early } \\
\text { diastolic mitral annular velocity }(E / E)\end{array}$ \\
\hline $\begin{array}{l}\text { Static handgrip, } \\
\text { dexmedetomidine, } \\
\text { glycopyrrolate, isoproterenol }\end{array}$ & NCT02524I45 & $n=45$ & $\begin{array}{l}\text { To determine the mechanisms of } \\
\text { chronotropic incompetence in patients } \\
\text { with HFpEF }\end{array}$ & Cardiac beta-receptor sensitivity \\
\hline
\end{tabular}

Abbreviations: CV, cardiovascular; HF, heart failure; NT-proBNP, N-terminal pro-brain natriuretic peptide; IL, interleukin; $\mathrm{VO}_{2}$, aerobic exercise capacity; HFpEF, heart failure with preserved ejection fraction; $\mathrm{VE} / \mathrm{VCO}_{2}$, ventilation efficiency/carbon dioxide ratio.

appropriate treatment of comorbidities, such as hypertension, myocardial ischemia, and ventricular rate control in atrial fibrillation. The guidelines also note that calcium channel blockers can be considered in patients with HFpEF for the treatment of the comorbidities listed earlier. However, in patients with HFrEF, these agents are contraindicated.

\section{ACE inhibitors}

The data on the use of ACE inhibitors for HFpEF are less clear than the information regarding its role in HFrEF.
Angiotensin II promotes ventricular hypertrophy and fibrosis, both of which are contributors to HFpEF, as well as vasoconstriction and vascular remodeling. ${ }^{34}$ By blocking the formation of angiotensin II, ACE inhibitors are a potential target for HFpEF treatment.

The Perindopril in Elderly People with Chronic Heart Failure study is the largest trial to date examining the use of ACE inhibitors in HFpEF. This double-blind, multicenter, placebo-controlled, randomized trial compared perindopril $4 \mathrm{mg}$ daily to placebo in 850 elderly patients with $\mathrm{HFpEF}$ with $\mathrm{CV}$ hospitalization 
within 6 months. The primary outcome was a composite of all-cause mortality and HF hospitalization. ${ }^{35}$ The study failed to meet sufficient power for its primary endpoint due to lower than expected enrollment and event rates and open-label ACE inhibitor use at 1 year. In the first year of follow-up, $15.3 \%$ of placebo patients and $10.8 \%$ of perindopril patients experienced a primary endpoint (HF 0.69; 95\% CI 0.47-1.01; $P=0.055$ ). In addition $12.4 \%$ of placebo patients and $8 \%$ perindopril patients experienced HF hospitalizations (HR 0.63; 95\% CI 0.41-0.97; $P=0.033$ ) at 1 year, but this was not significant for the entire study duration. The perindopril group also demonstrated significant improvements in functional class and 6-minute walk distance (6MWD) compared to placebo at 1 year. ${ }^{35}$ Unfortunately, the People with Chronic Heart Failure trial did not provide definitive evidence on morbidity and mortality outcomes for the use of ACE inhibitors in the HFpEF population.

Other smaller trials have demonstrated conflicting results for significant clinical benefits of ACE inhibitors. In a small study of 74 elderly patients with $\mathrm{HFpEF}$, quinapril use failed to demonstrate improvement in exercise tolerance, quality of life, worsening HF, or hospitalizations. ${ }^{36}$ In another small study of 21 elderly patients with HF with prior MI and normal EF, enalapril demonstrated improvement in New York Heart Association (NYHA) functional class, exercise duration, reduction of cardiothoracic ratio, and left ventricular mass compared to placebo. ${ }^{37}$

\section{Angiotensin receptor blockers}

ARBs, like ACE inhibitors, help blunt the adverse CV effects of angiotensin II. However, ARBs exert their effect further downstream and block the association of angiotensin II with its receptor AT1. Two large, randomized, double-blind, placebo-controlled trials have evaluated morbidity and mortality outcomes with ARB use in the HFpEF population. The Candesartan in Heart Failure Reduction in Mortality (CHARM)-Preserved trial randomized 3,023 patients with $\mathrm{HF}$ with NYHA function class II-IV, LVEF $>40 \%$, and history of cardiac hospitalization to receive candesartan (target dose $32 \mathrm{mg}$ once daily) or placebo. ${ }^{38}$ The primary outcome was CV death or HF hospitalization. The primary endpoint was met in $22 \%$ of candesartan patients and $24 \%$ of placebo patients (unadjusted HR 0.89; 95\% CI 0.77-1.03; $P=0.118$; adjusted HR $0.86 ; 95 \%$ CI $0.74-1.0 ; P=0.051)$. Fewer patients were admitted for one HF hospitalization $(P=0.017)$ and there were less total number of HF admissions $(P=0.014)$ in the candesartan group compared to placebo. The CHARM-Preserved trial was the first to demonstrate a moderate benefit for HF hospitalizations in the use of ARBs in the HFpEF population.
The I-PRESERVE trial followed the CHARM-Preserved trial but failed to support the potential improvement in clinical outcomes that CHARM-Preserved demonstrated. ${ }^{39}$ This trial enrolled 4,128 patients aged 60 years or above with HF, LVEF at least 45\%, NYHA class II-IV symptoms with an HF hospitalization 6 months prior to enrollment, or ongoing NYHA class III or IV symptoms without hospitalization. Patients were randomized to receive irbesartan (target dose $300 \mathrm{mg}$ daily) or placebo. The primary outcome was a composite of all-cause death or CV hospitalization. The primary outcome occurred in $36 \%$ of irbesartan patients and $37 \%$ of placebo patients (HR 0.95; 95\% CI 0.86-1.05; $P=0.35$ ). There was no significant difference in secondary endpoints including death, CV hospitalization, or worsening HF. The authors speculated that several factors might have contributed to the negative study results, including high rate of discontinuation and frequent use of other renin-angiotensin-aldosterone system agents including ACE inhibitors (in 40\% patients).

Two other small trials have examined ARB use in patients with HFpEF. Both studies examined the effects of an ARB (losartan or valsartan) on exercise tolerance in patients with HFpEF and demonstrated conflicting results compared to placebo. $^{40,41}$

\section{Aldosterone antagonists}

Aldosterone can promote interstitial collagen deposition and fibrosis, leading to ventricular stiffness. It is this mechanism that makes aldosterone antagonism an attractive strategy for the treatment of HFpEF. Several small studies looking at aldosterone antagonists in HFpEF showed improved $E / A$ ratio, decreased deceleration time, and decreased LV wall thickness. $^{42-44}$

The Aldo-DHF trial was a randomized, double-blind, placebo-controlled trial designed to assess the effect of spironolactone's ability to improve diastolic dysfunction and maximal exercise capacity in HFpEF. ${ }^{45}$ The trial included 422 ambulatory patients with NYHA II or III symptoms, LVEF $>50 \%$, diastolic dysfunction or atrial fibrillation at presentation, and peak $\mathrm{VO}_{2}$ of $\leq 25 \mathrm{~mL} / \mathrm{kg} / \mathrm{min}$. Patients who received spironolactone $25 \mathrm{mg}$ daily showed improved diastolic dysfunction $\left(E / E^{\prime}\right.$ decreased from 12.7 to 12.1 in spironolactone and increased from 12.8 to 13.6 in placebo over 12 months, $P<0.001$ for difference between groups) but no improvement in exercise capacity, patient symptoms, or quality of life.

The TOPCAT trial was a randomized, double-blind trial in which spironolactone was compared to placebo in 1,722 patients with $\mathrm{HFpEF}(\mathrm{EF} \geq 45 \%)$. ${ }^{46}$ All patients were required 
to be $\geq 50$ years of age and have recent hospitalization within 12 months prior to enrollment. A majority of enrolled patients had NYHA II symptoms, and the mean dose of spironolactone was $25 \mathrm{mg} / \mathrm{d}$. There was no difference with spironolactone versus placebo in the primary composite endpoint of death from CV causes, aborted cardiac arrest, or hospitalization for HF (18.6\% spironolactone vs $20.4 \%$ placebo, HR $0.89 ; 95 \%$ CI $0.77-1.04 ; P=0.14)$. When components of the primary outcome were evaluated individually, hospitalization for HF was significantly reduced with spironolactone versus placebo ( $12 \%$ vs $14.2 \%$, HR 0.83 ; 95\% CI 0.69-0.99; $P=0.04$ ). While the overall results of the TOPCAT trial were negative, there may be a role for spironolactone to reduce HF hospitalizations in HFpEF.

\section{Neprilysin inhibitors}

Neprilysin is an endopeptidase that degrades vasoactive peptides such as natriuretic peptides. Its inhibition blocks the degradation of vasoactive peptides. LCZ696, an angiotensin receptor neprilysin inhibitor, consists of a neprilysin inhibitor and valsartan in one compound and was studied in HFpEF within the PARAMOUNT trial. ${ }^{47}$ This was a Phase II, randomized, parallel group, double-blind, multicenter trial, comparing LCZ696, a neprilysin inhibitor $(n=134)$, to valsartan $(n=132)$ in patients with $\mathrm{HFpEF}(\mathrm{EF} \geq 45 \%)$. LCZ696 was titrated to $200 \mathrm{mg}$ twice daily and valsartan to $160 \mathrm{mg}$ twice daily, which was achieved in $81 \%$ and $79 \%$ of patients, respectively. LCZ696 showed reduction of primary endpoint, change in NT-pro BNP from baseline to 12 weeks versus placebo (783-605 pg/mL LCZ696 vs 862-835 pg/mL placebo, $P=0.005)$. The authors also noted improvement in LA remodeling and improvement in NYHA functional class at 36 weeks. However, hypothesis-generating larger scale trials should be completed before a role in HFpEF is determined. Sacubatril/valsartan (Entresto ${ }^{\mathrm{TM}}$ ) is an angiotensin receptor neprilysin inhibitor that is currently approved by the US FDA to reduce the risk of $\mathrm{CV}$ death and hospitalization for HF in patients with HFrEF (NYHA Class II-IV) but has no approved indication for HFpEF at this time.

\section{Beta-blockers}

The first trial to assess beta-blocker use in HFpEF evaluated the use of propranolol in a small $(n=158)$ study in patients with HFpEF (EF $\geq 40 \%$, mean EF 56\%). ${ }^{48,49}$ Propranolol $30 \mathrm{mg}$ three times daily showed a reduction in total mortality when compared to no propranolol ( $56 \%$ vs $76 \%, P=0.007)$ and a reduction in total mortality combined with nonfatal MI (59\% vs 65\%, $P=0.002)$. However, despite the reduction in total mortality, there was no significant difference in the cardiac deaths between groups. The SENIORS trial was a placebo-controlled trial comparing nebivolol's effect on the composite of all-cause mortality or hospitalization for CV causes and included both HFpEF and HFrEF patients. ${ }^{49}$ A subanalysis of this trial compared patients with HFpEF (EF $>35 \%$ ) versus HFrEF ( $\leq 35 \%$ ). The composite of allcause mortality or hospitalization for $\mathrm{CV}$ causes was not significantly different between patients with $\mathrm{HFpEF}(31.2 \%)$ and those with HFrEF (34.2\%), (HR 0.86; 95\% CI 0.72-1.04 vs HR $0.81 ; 95 \%$ CI $0.63-1.04, P=0.720)$. As this is a subanalysis, it is still not completely evident whether beta-blockers have the same evidence in HFrEF as in HFpEF.

Contrary to the mortality results of the 1997 propranolol study, the Japanese Diastolic Heart Failure Study included 245 patients with $\mathrm{LVEF}>40 \%$, randomized to either carvedilol or placebo. ${ }^{50}$ After a follow-up of 3.2 years, there was no significant difference in the composite of $\mathrm{CV}$ death and unplanned hospitalization for HF (24.2\% vs $27.2 \%$, HR 0.902 [95\% CI 0.543-1.486], $P=0.6854)$. A retrospective analysis of the OPTIMIZE-HF registry looked at a larger population than the previous studies to compare the use of betablockers on the composite endpoint of all-cause mortality or HF rehospitalization in 1,099 pairs of HFpEF propensitymatched patients ( $E F \geq 40 \%$, mean $55 \%$ ). ${ }^{51}$ During 6 years of follow-up, the beta-blocker group had no significant association with the composite endpoint of all-cause mortality or HF rehospitalization versus the no beta-blocker group (HR 1.01; 95\% CI 0.94-1.13, $P=0.569$ ).

Use of beta-blockers has been suggested to improve LVEF and NYHA symptoms and exercise capacity and improve $E / A$ ratio, but these results have not been consistently noted in large randomized, controlled trials..$^{48,49,52-54}$ The Effects of Long-term Administration of Nebivolol and the clinical symptoms, exercise capacity, and left ventricular function of patients with Diastolic Dysfunction (ELANND) trial goes against the idea that beta-blocker use might improve exercise capacity. ${ }^{55}$ ELANND was a multicenter, doubleblind, placebo-controlled, randomized, parallel group trial of 116 patients randomized to nebivolol versus placebo in patients with HFpEF (LVEF >45\%). Nebivolol showed no difference in the primary endpoint of change in 6MWD from baseline or peak oxygen uptake.

While improving diastolic filling time is one of the theories for the use of beta-blockers in HFpEF, it is unclear whether patients with higher heart rate have increased benefit with beta-blockers. The SWEDIC trial included 113 patients with HFpEF who were randomized to carvedilol $25 \mathrm{mg}$ twice daily 
( $50 \mathrm{mg}$ bid for patients $>85 \mathrm{~kg}$ ) versus placebo for 6 months. ${ }^{52}$ Carvedilol significantly increased age-adjusted $E / A$ ratio from baseline to 6 months versus placebo $(0.72-0.83$ carvedilol vs $0.71-0.76$ placebo, $P=0.046)$. Interestingly, the data were also analyzed by baseline heart rate. Patients with a heart rate $<71 \mathrm{bpm}$ did not have a significant increase in the $E / A$ ratio, while patients with a heart rate $>71 \mathrm{bpm}$ did have a significant increase in the $E / A$ ratio. This study did not meet its intended power, so its results should be interpreted with caution.

\section{Calcium channel blockers}

The ACCF/AHA HF guidelines caution that nondihydropyridine calcium channel blockers can be harmful in patients with $\mathrm{HFrEF}$ due to their negative inotropic effect. ${ }^{31}$ However, in patients with HFpEF where diastolic and not systolic dysfunction is the primary concern, the same logic may not be applicable. While limited by their size, a few trials have been conducted analyzing calcium channel blocker use in HFpEF.

In a 5-week placebo-controlled, crossover trial of 20 men with $\mathrm{HFpEF}$ (EF $>45 \%$ ) were assigned to verapamil or placebo. ${ }^{56}$ All patients were required to have HF symptoms for more than 3 months. Verapamil was titrated as tolerated to $120 \mathrm{mg}$ three times daily. Verapamil showed improvement in baseline HF score (median improvement 3 vs 1, $P<0.01)$, improvement in treadmill exercise capacity from baseline $(+13.9 \pm 4.3 \mathrm{vs}+10.7 \pm 3.4$ minute, $P<0.05,[\mathrm{n}=12])$, and improvement in LV peak filling rate from baseline (2.29 \pm 0.54 vs $1.85 \pm 0.45$ end diastolic volume/second). This study is difficult to extrapolate to a general HFpEF population given its small sample size and entirely male population.

As is the case with non-dihydropyridine calcium channel blockers, data for dihydropyridine calcium channel blockers is also limited. An analysis of the ALLHAT trial compared amlodipine, chlorthalidone, lisinopril, and doxazosin for the treatment of hypertension with regard to the occurrence of hospitalized HFpEF or HFrEF. ${ }^{57}$ There were 404 patients with $\mathrm{HFpEF}$ ( $\mathrm{EF} \geq 50 \%$ ). Chlorthalidone reduced the risk of HFpEF compared to amlodipine, lisinopril, or doxazosin (HR; 0.69 [95\% CI 0.53-0.91; $P<0.009$ ], 0.74 [95\% CI 0.56-0.97; $P<0.032$ ], and 0.53 [95\% CI 0.38-0.73; $P<0.001]$, respectively).

\section{Sildenafil}

Sildenafil is an inhibitor of phosphodiesterase-5 (PDE-5); this enzyme degrades cGMP. Increased availability of cGMP may provide benefits for both vascular and myocardial remodeling, including attenuating hypertrophy, fibrosis, and impaired cardiac relaxation. ${ }^{58}$ The RELAX trial was a multicenter, double-blind, placebo-controlled randomized trial examining the use of PDE-5 inhibition in HFpEF. ${ }^{59}$ The study randomized $216 \mathrm{HF}$ patients with $\mathrm{EF} \geq 50 \%$ and reduced exercise capacity to receive sildenafil (20 $\mathrm{mg}$ three times daily titrated to $60 \mathrm{mg}$ three times daily) or placebo. The primary outcome was change in peak oxygen consumption after 24 weeks of therapy. At the end of follow-up, median change in peak oxygen consumption $(-0.20 \mathrm{~mL} / \mathrm{kg} / \mathrm{min}$ [IQR -1.70 to 1.11$]$ for sildenafil versus $0.20 \mathrm{~mL} / \mathrm{kg} / \mathrm{min}$ [IQR -0.70 to 1.00 ] for placebo; $P=0.90)$, change in 6MWD (5.0 $\mathrm{m}$ for sildenafil vs $15.0 \mathrm{~m}$ for placebo; $P=0.92$ ), or clinical rank score ( 94.2 for sildenafil vs 95.8 for placebo; $P=0.85$ ) between placebo and sildenafil did not differ significantly.

Although the RELAX trial did not show significant improvement in exercise capacity, an earlier trial examined the use of sildenafil in patients with HFpEF on hemodynamic outcomes. Forty-four patients with $\mathrm{HFpEF}$ and pulmonary artery systolic pressure $>40 \mathrm{mmHg}$ were randomized to receive sildenafil $50 \mathrm{mg}$ three times daily or placebo. ${ }^{60} \mathrm{At}$ 6 months and 12 months, the sildenafil group demonstrated improvements in right heart and pulmonary hemodynamic endpoints, including mean pulmonary artery pressure (PAP), as well as quality-of-life scores. Another small, single-center trial examined the use of sildenafil titrated to $60 \mathrm{mg}$ three times daily or placebo in 52 patients with pulmonary hypertension due to HFpEF. There was no significant difference in mean PAP at 12 weeks, as well as other hemodynamic parameters included pulmonary arterial wedge pressure (PAWP), CO, and peak $\mathrm{VO}_{2}{ }^{61}$

\section{Riociguat}

Riociguat is a soluble guanylate cyclase (sGC) stimulator that targets the NO-soluble guanylate cyclase-cyclic guanosine monophosphate (NO-sGC-cGMP) signaling pathway. However, its mechanism is unique compared to that of the PDE-5 inhibitors. Riociguat directly stimulates sGC independent of endogenous NO, but also sensitizes sGC to endogenous NO as well. The DILATE-1 trial examined the use of riociguat in patients with HFpEF and pulmonary hypertension. ${ }^{62}$ Thirtysix HF patients with $\mathrm{LVEF}>50 \%$, mean PAP $\geq 25 \mathrm{mmHg}$, and PAWP $>15 \mathrm{mmHg}$ were randomized to receive one dose of placebo or riociguat at $0.5 \mathrm{mg}, 1 \mathrm{mg}$, or $2 \mathrm{mg}$. The primary outcome was peak decrease in mean PAP up to 6 hours after administration. While there was no significant change in the primary outcome $(P=0.6)$, riociguat $2 \mathrm{mg}$ significantly increased SV and cardiac index and decreased systolic blood pressure and right ventricular end-diastolic area. 
However, generalizing the results from a single-dose trial should be done with caution. There is an ongoing trial examining the use of another oral guanylate cyclase stimulator, vericiguat, in patients with HFpEF. The primary outcomes include change in NT-pro BNP and LA volume compared to placebo (BAY1021189).

\section{Nitrates}

The NEAT-HFpEF trial was a recent multicenter, randomized, placebo-controlled trial that examined the ability of isosorbide mononitrate to improve activity tolerance in patients with HFpEF. ${ }^{63}$ In this crossover study, 110 patients were randomized to receive isosorbide mononitrate titrated to $120 \mathrm{mg}$ daily or placebo over 6 weeks, with crossover for another 6 weeks. The primary endpoint was daily activity level, as defined by average daily accelerometer units. The isosorbide group demonstrated a nonsignificant decrease in daily activity and hours of activity per day compared to placebo. There was also no significant difference in 6MWD, quality-of-life scores, or NT-proBNP levels compared to placebo.

Two small studies ( $<30$ patients each) explored the use of inorganic nitrite and nitrate as an alternative source of bioactive $\mathrm{NO}$ over traditional organic nitrates for patients with HFpEF. ${ }^{64,65}$ Both studies demonstrated improvement in hemodynamic measures and exercise capacity with treatment. However, these small studies should be considered hypothesis-generating and not generalized to a larger population with long-term therapy.

\section{Digoxin}

The Digitalis Investigation Group (DIG) dataset looked specifically at the HFpEF population (EF 45\%) to compare digoxin $(n=496)$ versus placebo $(n=492)$ and found no difference in the combination of HF hospitalization or mortality, the combination of HF hospitalization or CV mortality, or mortality alone after a mean duration of 37 months. ${ }^{66}$ Given that there was a difference in hospitalization for HFrEF in the original trial, but not for HFpEF in the above-mentioned trial, a propensity-match population of 916 pairs of patients with HFrEF and HFpEF were analyzed ${ }^{67}$ The combined endpoint of HF hospitalization or mortality was similar in patients with HFrEF (HR 0.85; 95\% CI $0.67-1.08, P=0.188$ ) and those with HFpEF (HR 0.79; 95\% CI 0.60-1.03, $P=0.085$ ) with no significant interaction between digoxin and LVEF. The effect of digoxin on HF hospitalization was also similar between HFrEF (HR 0.80; 95\% CI 0.62-1.03, $P=0.79$ ) and HFpEF (HR 0.77; 95\% CI 0.57-1.03, $P=0.074$ ) irrespective of LVEF. However, after 2 years of follow-up digoxin, there was a significant benefit of digoxin on the combined endpoint of HF hospitalization or mortality. The authors suggest that the lack of benefit seen in the HFpEF subset of the initial trial was due to the sample size.

\section{Ranolazine}

The Ranolazine for the Treatment of Diastolic Heart Failure (RALI-DHF) trial was a small, prospective, single-center, randomized, double-blind, placebo-controlled, proofof-concept study evaluating the effect of ranolazine in 20 patients with HFpEF (LVEF $\geq 45 \%$ ). ${ }^{68}$ The intent of this trial was to determine whether ranolazine improved diastolic function in HFpEF patients. Patients received an IV bolus followed by continuous infusion of ranolazine or placebo for 24 hours and then transitioned to ranolazine $1,000 \mathrm{mg}$ twice daily or placebo. Ranolazine showed improvement in some measures of hemodynamics but no improvement in relaxation parameters. Larger studies are required before ranolazine could be recommended for the treatment of HFpEF.

\section{Ivabradine}

Ivabradine was approved by FDA in 2015 for the treatment of HFrEF to reduce hospitalizations for stable, symptomatic patients with heart rate $>70 \mathrm{bpm}$ on maximally tolerated beta-blockers. The role of ivabradine in HFpEF has not been established. The theory that patients with HFpEF may have detrimental effects from high heart rate during exercise due to reduced time for diastolic filling led to an analysis of ivabradine in HFpEF. Sixty-one patients with HFpEF (EF $\geq 50 \%$ ) were analyzed in a prospective, blinded, parallel-group, placebocontrolled trial to evaluate ivabradine's effect on exercise tolerance and LV function. ${ }^{69}$ Patients received either ivabradine $5 \mathrm{mg}$ twice daily or placebo for 7 days. Ivabradine improved exercise capacity from baseline $(4.2 \pm 1.8$ vs $5.7 \pm 1.9$ metabolic equivalent [METs], $P=0.001)$ and peak oxygen update $(14.0 \pm 6.2 \mathrm{~mL} / \mathrm{min} / \mathrm{kg}$ vs $17.0 \pm 3.3 \mathrm{~mL} / \mathrm{min} / \mathrm{kg}, P=0.001)$, with reduction in exercise-induced increase in the ratio of peak early diastolic mitral flow velocity ( $3.1 \pm 2.7$ vs $1.3 \pm 2.0, P=0.004)$. The drug showed improved exercise capacity from baseline compared to patients in the control group (1.5 \pm 1.2 vs $0.4 \pm 1.2$ METs, $P=0.001)$ and also improved peak oxygen uptake ( $3.0 \pm 3.6 \mathrm{ml} / \mathrm{kg} / \mathrm{min}$ vs $0.4 \pm 2.7 \mathrm{~mL} / \mathrm{kg} / \mathrm{min}, P=0.003$ ).

The utility of heart rate reduction with ivabradine in HFpEF patients has been questioned in a prospective, double-blind, randomized, crossover study. This study compared ivabradine $7.5 \mathrm{mg}$ twice daily versus placebo in 22 symptomatic HFpEF patients (LVEF $\geq 50 \%$ ) over 2 weeks, and the result was then compared with a paralleled study 
in 22 asymptomatic hypertensive volunteers. All HFpEF patients had objective evidence of exercise limitation (peak $\mathrm{VO}_{2}<80 \%$ ). Ivabradine worsened the primary endpoint of change in peak $\mathrm{VO}_{2}$ in the HFpEF cohort $(-2.1 \mathrm{~mL} / \mathrm{kg} \cdot \mathrm{min}$ vs $0.9 \mathrm{~mL} / \mathrm{kg} \cdot \mathrm{min}, P=0.003)$. There were no significant differences in secondary endpoints including tissue-Dopplerderived $E / E^{\prime}$ at echocardiography, plasma brain natriuretic peptide, and quality-of-life scores. Ivabradine did significantly reduce peak heart rate in response to exercise in the HFpEF (107 bpm vs 129 bpm; $P<0.0001)$ and hypertensive cohorts (127 bpm vs $145 \mathrm{bpm} ; P=0.003){ }^{70}$

The results of this study are in contrast to those seen in the earlier aforementioned study. The authors postulate that that latter study, having an older population ( 75 years vs 67 years), may represent a group more sensitive to heart rate reduction. The two studies also differ in ivabradine dose and duration of therapy. Larger trials using ivabradine for extended duration need to be conducted to determine a role in HFpEF.

\section{Statins}

While there are several studies published on the potential role of statins in $\mathrm{HFpEF}$, there are no randomized trials to support its use in routine clinical practice. The first trial to evaluate the effect of statin therapy in HFpEF included 137 patients with $\mathrm{EF} \geq 50 \%$. Patients treated with statins ( $\mathrm{n}=68)$ were compared to non-statin-treated patients $(n=69) .{ }^{71}$ Treatment with statins was associated with an improvement in survival (relative ratio $0.22,95 \%$ CI $0.07-0.64, P=0.006$ ). However, the study was not powered to detect a difference in mortality, and there were a low number of total events (only 20 deaths during the study period). Authors of this study caution that the benefits of statin therapy might reflect other unmeasured factors related to improved survival.

In an observational study of 13,533 Medicare patients with HFpEF (EF $>50 \%$ ), discharged on statin therapy was associated with improved 1- and 3-year mortality (relative ratio $0.69,95 \% \mathrm{CI} 0.61-0.78$; relative ratio 0.73 and $95 \% \mathrm{CI}$ $0.68-0.79$, respectively).$^{72}$ Improved mortality was reported to be independent of age, lipid levels, and comorbidities including coronary artery disease, diabetes, and hypertension. Given the observational nature of this study, the results should be interpreted with caution. In an analysis to determine whether statins are associated with improved outcomes after discharge from hospitalization for HF, 5,171 patients were stratified into four subgroups: patients with and without coronary artery disease, HFpEF $(n=706)$, and HFrEF. ${ }^{73}$ Statins were shown to be associated with improved outcomes for HF patients in the overall study population. However, in contrast to the previously mentioned studies, HFpEF patients had no difference in 5-year mortality in patients receiving statins versus those who were not ( $49 \%$ vs $55 \%, P=0.20)$. There was also no difference in the primary composite outcome of death from any cause, nonfatal MI, or nonfatal stroke (HR $0.92,95 \%$ CI $0.82-1.02, P=0.12$ ).

In a recent prospective study of $\mathrm{HFpEF}$ patients (EF $\geq 50 \%$ ), statin use was evaluated in a matched population of 2,074 statin users and 2,074 non-statin users. ${ }^{74}$ Statin use was associated with a higher rate of 1-year survival compared with those who were not treated ( $85.1 \%$ vs $80.9 \%$, HR 0.80 ; $95 \%$ CI $0.72-0.98, P<0.01)$. The statin group reduced CV death (HF 0.86; 95\% CI 0.75-0.98; $P=0.026)$ and reduced composite all-cause mortality (HR 0.89; 95\% CI 0.82-0.96; $P=0.003)$.

While the ACCF/AHA HF guidelines support the use of statin therapy for patients with known atherosclerotic disease, statins are not currently recommended for the treatment of HF alone in the absence of other indications for their use. ${ }^{31}$

\section{Device therapy}

Given that rises in LA pressure and pulmonary venous congestion are shown to herald an HF decompensation in patients with HFpEF and that the current mainstay of management includes volume management with diuretics, a patient management strategy utilizing ongoing direct or indirect measurements of LV filling pressures holds promise. The REDUCE LAP-HF trial (NCT0191361) with the objective to evaluate the safety and performance of the inter-atrial septal defect system in the treatment of HF patients with elevated left atrial pressure who remain symptomatic despite appropriate medical management just finished patient enrollment.

The CARDIOMEMS device is a wireless, implanted pulmonary artery pressure monitor implanted in the distal pulmonary artery during a right heart catheterization procedure. Patients transmit hemodynamic data daily using a wireless RF transmitter. In the CHAMPION trial, which was a single-blind clinical trial of the CARDIOMEMs device in patients with NYHA functional class III HF of any etiology, a management strategy using the hemodynamic data showed a significant reduction in HF hospitalizations. ${ }^{75}$ The CARDIOMEMs system has subsequently been approved in Europe and the United States.

\section{Conclusion}

HFpEF prevalence is increasing, and these patients face impaired health status while imposing a significant economic burden. To date, there is no approved therapy for these patients. 
There is an urgent need to focus on drug and device development for HFpEF. This would include characterizing HFpEF further to understand better clinical manifestations, contribution of comorbidities, and mechanisms. Developing longitudinal registries focused on collecting clinical, imaging, laboratory, treatment patterns, and outcomes data may facilitate this. ${ }^{76}$

\section{Disclosure}

The authors report no conflicts of interest in this work.

\section{References}

1. Steinberg BA, Zhao X, Heidenreich PA, et al; Get With the Guidelines Scientific Advisory Committee and Investigators. Trends in patients hospitalized with heart failure and preserved left ventricular ejection fraction: prevalence, therapies, and outcomes. Circulation. 2012;126(1):65-75.

2. Solomon SD, Anavekar N, Skali H, et al; Candesartan in Heart Failure Reduction in Mortality (CHARM) Investigators. Influence of ejection fraction on cardiovascular outcomes in a broad spectrum of heart failure patients. Circulation. 2005;112(24):3738-3744.

3. Campbell RT, Jhund PS, Castagno D, Hawkins NM, Petrie MC, McMurray JJ. What have we learned about patients with heart failure and preserved ejection fraction from DIG-PEF, CHARM-preserved, and I-PRESERVE? J Am Coll Cardiol. 2012;60(23):2349-2356.

4. Kawaguchi M, Hay I, Fetics B, Kass DA. Combined ventricular systolic and arterial stiffening in patients with heart failure and preserved ejection fraction: implications for systolic and diastolic reserve limitations. Circulation. 2003;107(5):714-720.

5. Melenovsky V, Borlaug BA, Rosen B, et al. Cardiovascular features of heart failure with preserved ejection fraction versus nonfailing hypertensive left ventricular hypertrophy in the urban Baltimore community: the role of atrial remodeling/dysfunction. $J$ Am Coll Cardiol. 2007;49(2):198-207.

6. Kovacs A, Papp Z, Nagy L. Causes and pathophysiology of heart failure with preserved ejection fraction. Heart Fail Clin. 2014;10(3): 389-398.

7. Paulus WJ, Tschope C. A novel paradigm for heart failure with preserved ejection fraction: comorbidities drive myocardial dysfunction and remodeling through coronary microvascular endothelial inflammation. J Am Coll Cardiol. 2013;62(4):263-271.

8. Borbely A, van der Velden J, Papp Z, et al. Cardiomyocyte stiffness in diastolic heart failure. Circulation. 2005;111(6):774-781.

9. Hidalgo C, Hudson B, Bogomolovas J, et al. PKC phosphorylation of titin's PEVK element: a novel and conserved pathway for modulating myocardial stiffness. Circ Res. 2009;105(7):631-638. [17 p following 638].

10. Kruger M, Kotter S, Grutzner A, et al. Protein kinase G modulates human myocardial passive stiffness by phosphorylation of the titin springs. Circ Res. 2009;104(1):87-94.

11. Campbell KS, Sorrell VL. Cell- and molecular-level mechanisms contributing to diastolic dysfunction in HFpEF. J Appl Physiol (1985). 2015;119(10):1228-1232.

12. Weber KT, Brilla CG, Janicki JS. Myocardial fibrosis: functional significance and regulatory factors. Cardiovasc Res. 1993;27(3): 341-348.

13. Guazzi M, Samaja M, Arena R, Vicenzi M, Guazzi MD. Long-term use of sildenafil in the therapeutic management of heart failure. $J \mathrm{Am}$ Coll Cardiol. 2007;50(22):2136-2144.

14. Weber T, O’Rourke MF, Ammer M, Kvas E, Punzengruber C, Eber B. Arterial stiffness and arterial wave reflections are associated with systolic and diastolic function in patients with normal ejection fraction. Am J Hypertens. 2008;21(11):1194-1202.
15. Borlaug BA, Kass DA. Ventricular-vascular interaction in heart failure. Cardiol Clin. 2011;29(3):447-459.

16. Schwartzenberg S, Redfield MM, From AM, Sorajja P, Nishimura RA, Borlaug BA. Effects of vasodilation in heart failure with preserved or reduced ejection fraction implications of distinct pathophysiologies on response to therapy. J Am Coll Cardiol. 2012;59(5):442-451.

17. Borlaug BA, Melenovsky V, Russell SD, et al. Impaired chronotropic and vasodilator reserves limit exercise capacity in patients with heart failure and a preserved ejection fraction. Circulation. 2006;114(20): 2138-2147.

18. Borlaug BA, Lam CS, Roger VL, Rodeheffer RJ, Redfield MM. Contractility and ventricular systolic stiffening in hypertensive heart disease insights into the pathogenesis of heart failure with preserved ejection fraction. J Am Coll Cardiol. 2009;54(5):410-418.

19. Yu CM, Lin H, Yang H, Kong SL, Zhang Q, Lee SW. Progression of systolic abnormalities in patients with "isolated" diastolic heart failure and diastolic dysfunction. Circulation. 2002;105(10):1195-1201.

20. Kraigher-Krainer E, Shah AM, Gupta DK, et al; PARAMOUNT Investigators. Impaired systolic function by strain imaging in heart failure with preserved ejection fraction. J Am Coll Cardiol. 2014;63(5): $447-456$.

21. Lam CS, Roger VL, Rodeheffer RJ, Borlaug BA, Enders FT, Redfield MM. Pulmonary hypertension in heart failure with preserved ejection fraction: a community-based study. $\mathrm{J} \mathrm{Am}$ Coll Cardiol. 2009;53(13):1119-1126.

22. Tedford RJ, Hassoun PM, Mathai SC, et al. Pulmonary capillary wedge pressure augments right ventricular pulsatile loading. Circulation. 2012;125(2):289-297.

23. Robbins IM, Hemnes AR, Pugh ME, et al. High prevalence of occult pulmonary venous hypertension revealed by fluid challenge in pulmonary hypertension. Circ Heart Fail. 2014;7(1):116-122.

24. Borlaug BA, Paulus WJ. Heart failure with preserved ejection fraction: pathophysiology, diagnosis, and treatment. Eur Heart $J$. 2011;32(6):670-679.

25. Paulus WJ, Tschope C, Sanderson JE, et al. How to diagnose diastolic heart failure: a consensus statement on the diagnosis of heart failure with normal left ventricular ejection fraction by the Heart Failure and Echocardiography Associations of the European Society of Cardiology. Eur Heart J. 2007;28(20):2539-2550.

26. Ky B, French B, May Khan A, et al. Ventricular-arterial coupling, remodeling, and prognosis in chronic heart failure. $\mathrm{J} \mathrm{Am} \mathrm{Coll} \mathrm{Cardiol}$. 2013;62(13):1165-1172.

27. Lang RM, Badano LP, Mor-Avi V, et al. Recommendations for cardiac chamber quantification by echocardiography in adults: an update from the American Society of Echocardiography and the European Association of Cardiovascular Imaging. Eur Heart J Cardiovasc Imaging. 2015;16(3):233-270.

28. Forfia PR, Watkins SP, Rame JE, Stewart KJ, Shapiro EP. Relationship between B-type natriuretic peptides and pulmonary capillary wedge pressure in the intensive care unit. $J$ Am Coll Cardiol. 2005; 45(10):1667-1671.

29. Kasner M, Westermann D, Steendijk P, et al. Utility of Doppler echocardiography and tissue Doppler imaging in the estimation of diastolic function in heart failure with normal ejection fraction: a comparative Doppler-conductance catheterization study. Circulation. 2007;116(6):637-647.

30. Flachskampf FA, Biering-Sorensen T, Solomon SD, Duvernoy O, Bjerner T, Smiseth OA. Cardiac imaging to evaluate left ventricular diastolic function. JACC Cardiovasc Imaging. 2015;8(9):1071-1093.

31. Yancy CW, Jessup M, Bozkurt B, et al. 2013 ACCF/AHA guideline for the management of heart failure: executive summary: a report of the American College of Cardiology Foundation/American Heart Association Task Force on practice guidelines. Circulation. 2013;128(16): $1810-1852$.

32. Lindenfeld J, Albert NM, Boehmer JP, et al. HFSA 2010 comprehensive heart failure practice guideline. J Card Fail. 2010;16(6): e1-e194. 
33. McMurray JJ, Adamopoulos S, Anker SD, et al; ESC Committee for Practice Guidelines. ESC guidelines for the diagnosis and treatment of acute and chronic heart failure 2012: The Task Force for the Diagnosis and Treatment of Acute and Chronic Heart Failure 2012 of the European Society of Cardiology. Developed in collaboration with the Heart Failure Association (HFA) of the ESC. Eur J Heart Fail. 2012;14(8):803-869.

34. Wright JW, Mizutani S, Harding JW. Pathways involved in the transition from hypertension to hypertrophy to heart failure. Treatment strategies. Heart Fail Rev. 2008;13(3):367-375.

35. Cleland JG, Tendera M, Adamus J, et al; PEP-CHF Investigators. The perindopril in elderly people with chronic heart failure (PEP-CHF) study. Eur Heart J. 2006;27(19):2338-2345.

36. Zi M, Carmichael N, Lye M. The effect of quinapril on functional status of elderly patients with diastolic heart failure. Cardiovasc Drugs Ther. 2003;17(2):133-139.

37. Aronow WS, Kronzon I. Effect of enalapril on congestive heart failure treated with diuretics in elderly patients with prior myocardial infarction and normal left ventricular ejection fraction. Am J Cardiol. 1993;71(7):602-604.

38. Yusuf S, Pfeffer MA, Swedberg K, et al; CHARM Investigators and Committees. Effects of candesartan in patients with chronic heart failure and preserved left-ventricular ejection fraction: the CHARM-Preserved Trial. Lancet. 2003;362(9386):777-781.

39. Massie BM, Carson PE, McMurray JJ, et al; I-PRESERVE Investigators. Irbesartan in patients with heart failure and preserved ejection fraction. N Engl J Med. 2008;359(23):2456-2467.

40. Warner JG Jr, Metzger DC, Kitzman DW, Wesley DJ, Little WC. Losartan improves exercise tolerance in patients with diastolic dysfunction and a hypertensive response to exercise. J Am Coll Cardiol. 1999;33(6):1567-1572.

41. Parthasarathy HK, Pieske B, Weisskopf M, et al. A randomized, doubleblind, placebo-controlled study to determine the effects of valsartan on exercise time in patients with symptomatic heart failure with preserved ejection fraction. Eur J Heart Fail. 2009;11(10):980-989.

42. Roongsritong C, Sutthiwan P, Bradley J, Simoni J, Power S, Meyerrose GE. Spironolactone improves diastolic function in the elderly. Clin Cardiol. 2005;28(10):484-487.

43. Mottram PM, Haluska B, Leano R, Cowley D, Stowasser M, Marwick TH. Effect of aldosterone antagonism on myocardial dysfunction in hypertensive patients with diastolic heart failure. Circulation. 2004;110(5): 558-565.

44. Mak GJ, Ledwidge MT, Watson CJ, et al. Natural history of markers of collagen turnover in patients with early diastolic dysfunction and impact of eplerenone. J Am Coll Cardiol. 2009;54(18):1674-1682.

45. Edelmann F, Wachter R, Schmidt AG, et al; Aldo-DHF Investigators. Effect of spironolactone on diastolic function and exercise capacity in patients with heart failure with preserved ejection fraction: the Aldo-DHF randomized controlled trial. JAMA. 2013;309(8): 781-791.

46. Pitt B, Pfeffer MA, Assmann SF, et al; TOPCAT Investigators. Spironolactone for heart failure with preserved ejection fraction. $\mathrm{NEngl}$ J Med. 2014;370(15):1383-1392.

47. Solomon SD, Zile M, Pieske B, et al; Prospective comparison of ARNI with ARB on Management Of heart failUre with preserved ejectioN fracTion (PARAMOUNT) Investigators. The angiotensin receptor neprilysin inhibitor LCZ696 in heart failure with preserved ejection fraction: a phase 2 double-blind randomised controlled trial. Lancet. 2012;380(9851):1387-1395.

48. Aronow WS, Ahn C, Kronzon I. Effect of propranolol versus no propranolol on total mortality plus nonfatal myocardial infarction in older patients with prior myocardial infarction, congestive heart failure, and left ventricular ejection fraction $>$ or $=40 \%$ treated with diuretics plus angiotensin-converting enzyme inhibitors. Am J Cardiol. 1997;80(2):207-209.
49. van Veldhuisen DJ, Cohen-Solal A, Bohm M, et al; SENIORS Investigators. Beta-blockade with nebivolol in elderly heart failure patients with impaired and preserved left ventricular ejection fraction: data from SENIORS (study of effects of nebivolol intervention on outcomes and rehospitalization in seniors with heart failure). J Am Coll Cardiol. 2009;53(23):2150-2158.

50. Yamamoto K, Origasa H, Hori M, Investigators JD. Effects of carvedilol on heart failure with preserved ejection fraction: the Japanese Diastolic Heart Failure Study (J-DHF). Eur J Heart Fail. 2013;15(1):110-118.

51. Patel K, Fonarow GC, Ekundayo OJ, et al. Beta-blockers in older patients with heart failure and preserved ejection fraction: class, dosage, and outcomes. Int J Cardiol. 2014;173(3):393-401.

52. Bergstrom A, Andersson B, Edner M, Nylander E, Persson H, Dahlstrom U. Effect of carvedilol on diastolic function in patients with diastolic heart failure and preserved systolic function. Results of the Swedish Doppler-echocardiographic study (SWEDIC). Eur J Heart Fail. 2004;6(4):453-461

53. Nodari S, Metra M, Dei Cas L. Beta-blocker treatment of patients with diastolic heart failure and arterial hypertension. A prospective, randomized, comparison of the long-term effects of atenolol vs nebivolol. Eur J Heart Fail. 2003;5(5):621-627.

54. Takeda Y, Fukutomi T, Suzuki S, et al. Effects of carvedilol on plasma B-type natriuretic peptide concentration and symptoms in patients with heart failure and preserved ejection fraction. Am J Cardiol. 2004;94(4):448-453.

55. Conraads VM, Metra M, Kamp O, et al. Effects of the long-term administration of nebivolol on the clinical symptoms, exercise capacity, and left ventricular function of patients with diastolic dysfunction: results of the ELANDD study. Eur J Heart Fail. 2012;14(2):219-225.

56. Setaro JF, Zaret BL, Schulman DS, Black HR, Soufer R. Usefulness of verapamil for congestive heart failure associated with abnormal left ventricular diastolic filling and normal left ventricular systolic performance. Am J Cardiol. 1990;66(12):981-986.

57. Davis BR, Kostis JB, Simpson LM, et al; ALLHAT Collaborative Research Group. Heart failure with preserved and reduced left ventricular ejection fraction in the antihypertensive and lipid-lowering treatment to prevent heart attack trial. Circulation. 2008;118(22):2259-2267.

58. Kanwar M, Agarwal R, Barnes M, et al. Role of phosphodiesterase-5 inhibitors in heart failure: emerging data and concepts. Curr Heart Fail Rep. 2013;10(1):26-35.

59. Redfield MM, Chen HH, Borlaug BA, et al; RELAX Trial. Effect of phosphodiesterase-5 inhibition on exercise capacity and clinical status in heart failure with preserved ejection fraction: a randomized clinical trial. JAMA. 2013;309(12):1268-1277.

60. Guazzi M. Pulmonary hypertension in heart failure preserved ejection fraction: prevalence, pathophysiology, and clinical perspectives. Circ Heart Fail. 2014;7(2):367-377.

61. Hoendermis ES, Liu LC, Hummel YM, et al. Effects of sildenafil on invasive haemodynamics and exercise capacity in heart failure patients with preserved ejection fraction and pulmonary hypertension: a randomized controlled trial. Eur Heart J. 2015;36(38):2565-2573.

62. Bonderman D, Pretsch I, Steringer-Mascherbauer R, et al. Acute hemodynamic effects of riociguat in patients with pulmonary hypertension associated with diastolic heart failure (DILATE-1): a randomized, double-blind, placebo-controlled, single-dose study. Chest. 2014; 146(5):1274-1285

63. Redfield MM, Anstrom KJ, Levine JA, et al; NHLBI Heart Failure Clinical Research Network. Isosorbide mononitrate in heart failure with preserved ejection fraction. N Engl J Med. 2015;373:2314-2324.

64. Borlaug BA, Koepp KE, Melenovsky V. Sodium nitrite improves exercise hemodynamics and ventricular performance in heart failure with preserved ejection fraction. J Am Coll Cardiol. 2015;66(15):1672-1682.

65. Zamani P, Rawat D, Shiva-Kumar P, et al. Effect of inorganic nitrate on exercise capacity in heart failure with preserved ejection fraction. Circulation. 2015;131(4):371-380. 
66. Ahmed A, Rich MW, Fleg JL, et al. Effects of digoxin on morbidity and mortality in diastolic heart failure: the ancillary digitalis investigation group trial. Circulation. 2006;114(5):397-403.

67. Meyer P, White M, Mujib M, et al. Digoxin and reduction of heart failure hospitalization in chronic systolic and diastolic heart failure. Am J Cardiol. 2008;102(12):1681-1686.

68. Maier LS, Layug B, Karwatowska-Prokopczuk E, et al. RAnoLazIne for the treatment of diastolic heart failure in patients with preserved ejection fraction: the RALI-DHF proof-of-concept study. JACC Heart Fail. 2013;1(2):115-122.

69. Kosmala W, Holland DJ, Rojek A, Wright L, Przewlocka-Kosmala M, Marwick TH. Effect of If-channel inhibition on hemodynamic status and exercise tolerance in heart failure with preserved ejection fraction: a randomized trial. J Am Coll Cardiol. 2013;62(15):1330-1338.

70. Pal N, Sivaswamy N, Mahmod M, et al. Effect of selective heart rate slowing in heart failure with preserved ejection fraction. Circulation. 2015;132(18):1719-1725.

71. Fukuta H, Sane DC, Brucks S, Little WC. Statin therapy may be associated with lower mortality in patients with diastolic heart failure: a preliminary report. Circulation. 2005;112(3):357-363.
72. Shah R, Wang Y, Foody JM. Effect of statins, angiotensin-converting enzyme inhibitors, and beta blockers on survival in patients $>$ or $=65$ years of age with heart failure and preserved left ventricular systolic function. Am J Cardiol. 2008;101(2):217-222.

73. Ouzounian M, Tu JV, Austin PC, Chong A, Liu PP, Lee DS. Statin therapy and clinical outcomes in heart failure: a propensity-matched analysis. J Card Fail. 2009;15(3):241-248.

74. Alehagen U, Benson L, Edner M, Dahlstrom U, Lund LH. Association between use of statins and mortality in patients with heart failure and ejection fraction of $>/=50$. Circ Heart Fail. 2015;8(5):862-870.

75. Abraham WT, Adamson PB, Bourge RC, et al; CHAMPION Trial Study Group. Wireless pulmonary artery haemodynamic monitoring in chronic heart failure: a randomised controlled trial. Lancet. 2011;377(9766):658-666.

76. Butler J, Fonarow GC, Zile MR, et al. Developing therapies for heart failure with preserved ejection fraction: current state and future directions. JACC Heart Fail. 2014;2(2):97-112.
Vascular Health and Risk Management

\section{Publish your work in this journal}

Vascular Health and Risk Management is an international, peerreviewed journal of therapeutics and risk management, focusing on concise rapid reporting of clinical studies on the processes involved in the maintenance of vascular health; the monitoring, prevention and treatment of vascular disease and its sequelae; and the involvement of

\section{Dovepress}

metabolic disorders, particularly diabetes. This journal is indexed on PubMed Central and MedLine. The manuscript management system is completely online and includes a very quick and fair peer-review system, which is all easy to use. Visit http://www.dovepress.com/ testimonials.php to read real quotes from published authors. 